\title{
Molecular Characterization of a Begomovirus, $\alpha$-Satellite, and $\beta$-Satellite Associated with Leaf Curl Disease of Parthenium hysterophorus in India
}

Susheel Kumar, Plant Molecular Virology Laboratory, Centre for Plant Molecular Biology Division, Council of Scientific and Industrial Research-National Botanical Research Institute (CSIR-NBRI), Lucknow-226001, U.P., India; Ashish Srivastava, Department of Plant Molecular Biology, University of Delhi South Campus; and Plant Molecular Virology Laboratory, CSIR-NBRI, Lucknow-226001, U.P., India; Meraj Jaidi and Puneet Singh Chauhan, Division of Plant-Microbe Interactions, CSIR-NBRI, Lucknow-226001, U.P., India; and S. K. Raj, Plant Molecular Virology Laboratory, CSIR-NBRI, Lucknow-226001, U.P., India

\begin{abstract}
Kumar, S., Srivastava, A., Jaidi, M., Chauhan, P. S., and Raj, S. K. 2016. Molecular characterization of a begomovirus, $\alpha$-satellite, and $\beta$-satellite associated with leaf curl disease of Parthenium hysterophorus in India. Plant Dis. 100:2299-2305.

Parthenium hysterophorus plants exhibiting severe leaf curl and stunting symptoms were observed near agriculture fields in Lucknow, India. The association of a begomovirus, $\beta$-satellite, and $\alpha$-satellite with these symptoms of a Parthenium disease was investigated by sequence analyses of virus and satellite DNA amplified by rolling circle amplification and polymerase chain reaction. The highest sequence identities and closest phylogenetic relationships for the begomovirus, $\beta$-satellite, and $\alpha$-satellite detected in $P$. hysterophorus plants were to Tomato leaf curl virus (ToLCV), papaya leaf curl $\beta$-satellite (PaLCuB), and Ageratum yellow vein India $\alpha$-satellite (AYVIA), respectively. These findings identified the virus and satellites infecting the

Parthenium sp. as ToLCV, PaLCuB, and AYVIA, respectively. P. hysterophorus and tomato seedlings infected with cloned ToLCV, PaLCuB, and AYVIA by agroinoculation developed leaf curl symptoms, whereas plants infected with ToLCV alone or with ToLCV and AYVIA developed mild yellowing. The results show that this complex infects and causes disease in $P$. hysterophorus and tomato. P. hysterophorus is an invasive weed commonly found around agricultural fields and along roadsides in India. These results indicate that $P$. hysterophorus plants infected with ToLCV and associated satellite DNA act as an alternate host (reservoir), and that could lead to increased incidence of tomato leaf curl disease.
\end{abstract}

Parthenium hysterophorus (family Asteraceae), commonly known as carrot grass or congress grass in India, is an annual or short-lived perennial plant that is native to the American tropics (http://www. cabi.org/isc/datasheet/45573). It is an invasive species in India and spread is of almost epidemic proportions, with reports from all states of India (Gnanavel 2013) and with crop production, livestock, and human health affected (Akhtar et al. 2010; Morin et al. 2009; Sharma et al. 2005; Singh et al. 2003). Few viruses have been reported to infect $P$. hysterophorus. $P$. hysterophorus has been reported as a symptomless carrier of Tobacco streak virus (TSV) in Australia by Sharman et al. (2009). In southern India, it has also been reported as a symptomless carrier of TSV and to play a major role in the spread of TSV in groundnut in (Prasada-Rao et al. 2003). However, infection of $P$. hysterophorus with a begomovirus has not been reported previously.

Viruses in the family Geminiviridae have circular, single-stranded genomes encapsidated in twinned icosahedral (geminate) virions. Geminiviruses transmitted by the whitefly Bemisia tabaci (Gennadius) are in the genus Begomovirus and infect a wide range of crops, including tomato (Lapidot et al. 2014; Moffat 1999). Begomoviruses have either a monopartite or bipartite genome organization (Fauquet et al. 2003). Monopartite begomoviruses have genomes consisting of a single component that encodes six genes: two in the virion sense (V1 [capsid protein] and V2 [precapsid protein]) and four in the complementary sense ( $\mathrm{C} 1$ [replication-associated protein], $\mathrm{C} 2$ [transcription

Corresponding authors: S. K. Raj; E-mail: skraj2@rediffmail.com; and S. Kumar, E-mail: susheelnbri@gmail.com

S. Kumar and A. Srivastava equally contributed for this study.

*The $\boldsymbol{e}$-Xtra logo stands for "electronic extra" and indicates that two supplementary figures are published online.

Accepted for publication 16 June 2016.

http://dx.doi.org/10.1094/PDIS-09-15-0982-RE

(C) 2016 The American Phytopathological Society activator protein], C3 [replication enhancer protein], and $\mathrm{C} 4$ [C4 protein]). Monopartite begomoviruses may associate approximately $1.4 \mathrm{~kb}$ (half the genome size of the helper begomovirus) singlestranded DNA molecules known as $\beta$-satellites and $\alpha$-satellites (Briddon et al. 2000; Huang et al. 2013; Mansoor et al. 2003). The $\beta$-satellites are symptom-modulating and are widespread across the Old World (Briddon et al. 2008). The $\beta C 1$ gene encoded by the $\beta$-satellites has important roles in symptom induction and suppression of transcriptional and posttranscriptional gene silencing, and can affect jasmonic-acid-responsive genes (Zhou 2013). The $\alpha$-satellites are self-replicating satellite-like molecules that are dependent on a helper virus for movement in and between plants. The $\alpha$-satellites occur with monopartite begomoviruses and $\beta$-satellites in the Old World (Briddon et al. 2004; Nawaz-ul-Rehman et al. 2012) and with bipartite begomoviruses (but no $\beta$-satellites) in the New World (Paprotka et al. 2010). The precise function of $\alpha$-satellites is unclear (Zhou 2013). However, Nawaz-ul-Rehman et al. (2010) showed that $\alpha$-satellites may be involved in overcoming RNA-mediated host defense and attenuating symptoms of the helper virus. The work of Nawaz-ul-Rehman et al. (2010) also showed that some $\alpha$-satellites suppress posttranscriptional gene silencing (host defense).

Here, we report the occurrence of a tomato-infecting begomovirus (Tomato leaf curl virus [ToLCV]) together with papaya leaf curl $\beta$-satellite $(\mathrm{PaLCuB})$ and Ageratum yellow vein India $\alpha$-satellite (AYVIA) in P. hysterophorus plants with severe leaf curl and stunting symptoms. We further confirm that the cloned DNA of ToLCV and $\mathrm{PaLCuB}$ cause leaf curl disease in P. hysterophorus.

\section{Materials and Methods}

Sample collection and detection of a begomovirus. A survey was conducted of weeds growing near agricultural fields around Lucknow in the year 2012 and leaf curl disease symptoms were observed on $P$. hysterophorus plants. Leaf samples were collected from 15 randomly selected symptomatic and 15 nonsymptomatic plants. For detection of Begomovirus spp., total genomic DNA was isolated using GenElute Plant genomic DNA miniprep kit (Sigma-Aldrich) and polymerase chain reaction (PCR) was performed with Begomovirusspecific degenerate primers PALIv1978 and PARIc496 following the 
described conditions (Rojas et al. 1993). All these samples were also checked for the presence of a begomovirus DNA B component with the primers $\mathrm{BC} 1 \mathrm{~F}$ and $\mathrm{BC} 1 \mathrm{R}$ (Padidam et al. 1995), $\beta$-satellite DNA with primers Beta 01 and Beta 02 (Briddon et al. 2003), and $\alpha$-satellite DNA with the primers DNA101 and DNA202 (Bull et al. 2003) following the recommended conditions. All PCR products were analyzed by electrophoresis in $1.0 \%$ agarose gels with the 1-kb DNA ladder (Thermo Fisher Scientific Inc.) as size markers.

Complete genome sequencing and sequence analysis. The fulllength begomovirus genome was amplified from the DNA isolated from 15 symptomatic samples by the rolling circle amplification (RCA) method using an Illustra TempliPhi Amplification kit (GE Healthcare). The resulting products were digested with BamHI, XbaI, DraI, and $\mathrm{XhoI}$ and analyzed by electrophoresis in $1.5 \%$ agarose gels to identify enzymes to clone full-length genomic DNA. Putative fulllength (approximately $2.7 \mathrm{~kb}$ ) amplicons from three randomly selected samples were cloned into the pCAMBIA1300 vector digested with the appropriate enzyme. The cloned begomovirus genome and approximately 1.4-kb DNA fragments obtained by PCR using $\alpha$-satellite- and $\beta$-satellite-specific primers were sequenced and deposited in GenBank.

The sequences were compared with those publically available in the National Center for Biotechnology Information sequence database by BLASTn analysis for sequence identities. The open reading frames (ORF) located in the genome and their predicted amino acid sequences were analyzed with the ORF finder (www.ncbi.nlm.nih. gov/orffinder/) and ExPasy (http://www.expasy.org/resources/ search/keywords:translation) tools, respectively. The species demarcation tool (Muhire et al. 2014) was used with default parameters to obtain the specific nucleotide sequence identity of the begomovirus, $\alpha$-satellite, and $\beta$-satellites identified here with respective sequences of DNA molecules. The amino acid identities of protein-coding ORF of these molecules were obtained by the DiAlign tool (http:// www.genomatix.de/cgi-bin/dialign/dialign.pl). The evolutionary history was inferred using the maximum-parsimony method and the tree was obtained using the Close-Neighbor-Interchange algorithm in MEGA v6.1 program (Tamura et al. 2013).

Preparation of clones for agroinoculation. Constructs for the infectivity of the begomovirus were produced by digesting the clone with BamHI and HindIII and ligating the resulting 2,694-bp fragment into the pCAMBIA1300 vector. Then, the full-length genomic 2,760-bp BamHI fragment was ligated at the BamHI site in the sense orientation. For preparation of infectious clones of the $\alpha$-satellite and $\beta$-satellite, the RCA-amplified DNA were partially digested with SmaI and EcoRI, respectively, which produced an approximately
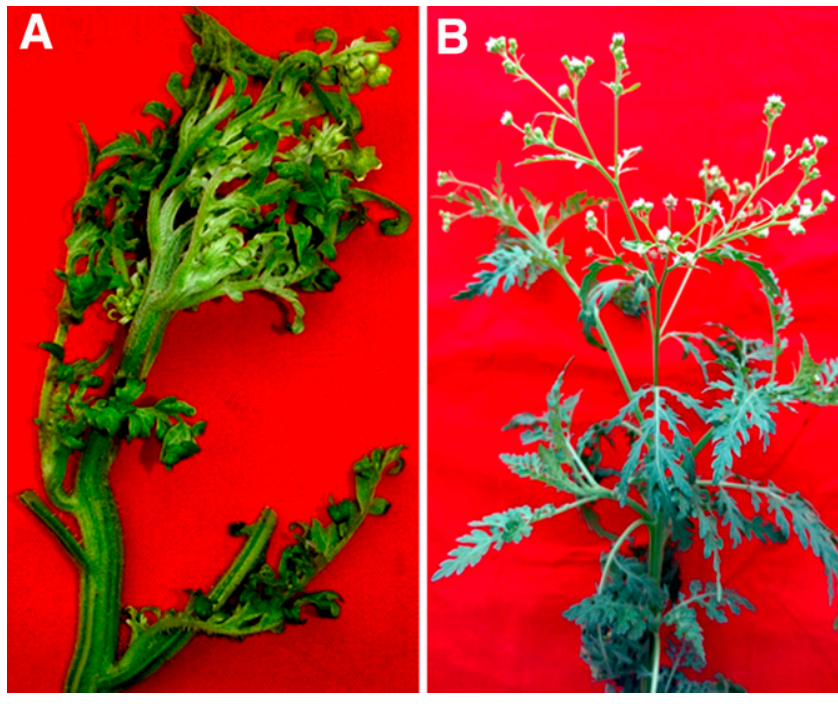

Fig. 1. Naturally infected Parthenium hysterophorus showing A, severe leaf curl, shortening and swelling of internodes, and stunting symptoms as compared with $\mathbf{B}$, a healthy plant. 1.4-kb monomer and approximately 2.8 -kb dimer. The dimers of approximately $2.8 \mathrm{~kb}$ recovered from both digestions were eluted independently and ligated at their respective cloning sites of pCAMBIA1300 vector. The constructs for the infectivity of the begomovirus, $\beta$-satellite, and $\alpha$-satellite will henceforth be referred to as Par-A, Par- $\beta$, and Par- $\alpha$, respectively. pCAMBIA1300 constructs were mobilized into Agrobacterium tumefaciens (GV3101) and agroinoculated by the syringe infiltration method (in combination or separately) into leaf lamina of $P$. hysterophorus and Solanum lycopersicum ('Pusa Ruby') seedlings at the four- to six-leaf stage. The infiltrated plants were kept in glasshouse conditions (natural illumination with temperature of $25 \pm 2^{\circ} \mathrm{C}$ ) and examined regularly for appearance of symptoms. The experiments were repeated three times with 10 plants of each species for each inoculum.

\section{Results}

Disease symptoms and begomovirus detection. During the survey conducted in 2012, an outbreak of leaf curl disease symptoms was observed on a number of $P$. hysterophorus plants growing in the vicinity of tomato fields and along roads in Lucknow, India. The disease incidence was about $25 \%$ and diseased plants exhibited severe leaf curling, enation, twisting of leaves, shortening and swelling of internodes, and stunting symptoms (Fig. 1). The disease symptoms in these plants were similar to those in other plants induced by begomoviruses. Whiteflies were also observed on $P$. hysterophorus plants (with and without symptoms). Based on typical begomovirus-like (leaf curl) symptoms, the causal agent was suspected to be a Begomovirus sp.

Begomoviruses were detected by PCR using begomovirus-specific primers. PCR with begomovirus-specific primers resulted in amplification of approximately 1.2-kb DNA fragments from all 15 symptomatic samples, suggesting begomovirus infection, whereas no fragment was amplified from any of the 15 nonsymptomatic plants. All samples were also assessed for the presence of a DNA-B component by PCR with specific primers. Because no DNA fragments were amplified from any of the 15 samples, this suggested the begomovirus was monopartite.

Characterization of the begomovirus associated with $P$. hysterophorus. RCA products obtained from all 15 symptomatic leaf samples were digested with BamHI, XbaI, DraI, and XhoI. The expected approximately 2.7-kb DNA fragment was observed in all samples following digestion with BamHI only. The approximately 2.7-kb fragments from three randomly selected samples were cloned and sequenced. The sequences of three isolates were identical to each other; therefore, the 2,760-nucleotide (nt) sequence of one isolate (from P. hysterophorus isolate SKR11) was deposited in the GenBank database under accession number JX524172. Analysis of the sequence revealed that the begomovirus characterized here contains six open reading frames- $\mathrm{V} 1$ and $\mathrm{V} 2$ in the virion sense and $\mathrm{C} 1, \mathrm{C} 2, \mathrm{C} 3$, and $\mathrm{C} 4$ in the complementary sense-and an intergenic region.

BLASTn analysis of the sequence of the SKR11 isolate revealed highest nucleotide identity (97\%) with various isolates of ToLCV (HM007094, JX987088, HM803118, and HM851186) reported from India. Pairwise sequence comparison of the SKR11 isolate with ToLCV and other close begomovirus members (appeared in BLASTn) was also performed (Table 1). The isolate shared the highest sequence identity (97.3\%) with ToLCV-[In:Ban: Chi:08] (HM007094) reported on Capsicum spp. from India and between 97.2 and $91.7 \%$ sequence identity with other ToLCV isolates reported from India (Table 1).

To determine the phylogenetic relationship of the SKR11 isolate with other close begomoviruses, phylogeny was done using the MEGA v6.1 program. The SKR11 isolate showed the closest relationship with isolate of ToLCV-[In:Luc:Zin:12] (JX987088) from Zinnia elegans in India and close relationships with other ToLCV isolates considered for this study (Fig. 2). Based on high sequence identity, close phylogenetic relationships, and begomovirus species demarcation criteria of $>91 \%$ identity recommended by the International Committee on Taxonomy of Viruses (ICTV) Geminiviridae study group (Brown et al. 2015), the begomovirus isolate SKR11 was identified as an isolate of ToLCV, for which the isolate descriptor ToLCV-[In:Lko:Par:12] is proposed. 
Characterization of satellite molecules associated with P. hysterophorus. Because monopartite begomoviruses are reported to be associated with satellites, PCR analyses with $\alpha$-satellite- and $\beta$-satellite-specific primers were performed with three DNA samples of infected P. hysterophorus (from which the begomovirus genome was amplified). Both primer pairs directed the amplification of approximately 1.4-kb DNA fragments from all three infected samples, which indicated the association of both an $\alpha$-satellite and a $\beta$-satellite with

Table 1. Percent sequence identity of Tomato leaf curl virus (ToLCV)-[In:Lko:Par:12] (JX524172) isolate with other selected begomoviruses at the level of complete genome (nucleotide sequence identity) and encoded proteins (amino acid sequence identity)

\begin{tabular}{|c|c|c|c|c|c|c|c|c|c|c|}
\hline Accessions & Acronyms (isolate descriptors) ${ }^{a}$ & Host & Location & DNA genome & $\mathbf{V 2}$ & V1 & $\mathbf{C 3}$ & $\mathrm{C2}$ & C1 & C4 \\
\hline НМ007094 & ToLCV-[In:Ban:Chi:08] & Capsicum spp. & India & 97.3 & 100 & 99.6 & 97.8 & 97.0 & 95.0 & 96.9 \\
\hline JX987088 & ToLCV-[In:Luc:Zin:12] & Zinnia elegance & India & 97.2 & 98.3 & 99.2 & 92.5 & 91.8 & 93.6 & 96.9 \\
\hline HМ803118 & ToLCV-[In:ND:Tom:10] & Solanum lycopersicum & India & 96.7 & 100 & 100 & 97.8 & 98.5 & 94.2 & 89.7 \\
\hline HM851186 & ToLCV-[In:ND:Tom:10] & S. lycopersicum & India & 96.6 & 99.2 & 99 & 97.8 & 98.5 & 93.9 & 90.7 \\
\hline U38239 & ToLCV-[In:Ban:Tom:02] & S. lycopersicum & India & 96.3 & 100 & 99.2 & 97.0 & 95.5 & 92.2 & 95.9 \\
\hline JX678965 & ToLCV-[In:Kar:SF:12] & Helianthus annuus & India & 95.1 & 98.3 & 99.2 & 98.5 & 95.5 & 89.8 & 86.6 \\
\hline FJ914798 & ToLCV-[In:Pin:Men:11] & Mentha viridis & India & 93.3 & 92.4 & 95.7 & 94.8 & 97.0 & 95.6 & 97.9 \\
\hline AY754812 & ToLCV-[In:Jan:Tom:06] & S. lycopersicum & India & 91.7 & 97.5 & 99.2 & 97.0 & 94.8 & 86.4 & 87.6 \\
\hline GU199584 & TbCSV-[CN:Mir:09] & Mirabilis jalapa & China & 87.6 & 95.8 & 96.5 & 85.1 & 84.3 & 90.3 & 80.4 \\
\hline HG003650 & TbCSV-[CN:Yun:Age:13] & Ageratum conyzoides & China & 87.4 & 94.8 & 97.7 & 85.1 & 84.3 & 89.8 & 78.4 \\
\hline KF551584 & TbCSV-[CN:Mir:09] & M. jalapa & China & 87.1 & 93.2 & 96.9 & 87.3 & 88.1 & 80.8 & 76.8 \\
\hline GU199583 & TbCSV-[CN:Alt:09] & $\begin{array}{l}\text { Alternanthera } \\
\text { philoxeroides }\end{array}$ & China & 87.0 & 92.2 & 96.1 & 84.3 & 81.3 & 89.2 & 77.3 \\
\hline KF551575 & TLCKerV-[In:ND:Tom:13] & S. lycopersicum & India & 86.2 & 92.4 & 96.5 & 93.3 & 92.5 & 88.4 & 47.9 \\
\hline EU910141 & ToLCKeV-[In:Ker:Tom:05] & S. lycopersicum & India & 86.1 & 92.4 & 94.9 & 93.3 & 93.3 & 79.7 & 46.9 \\
\hline GQ268327 & AEV-[In:Gor:Par:08] & Trichosanthes dioica & India & 86.1 & 96.5 & 97.3 & 85.8 & 84.3 & 82.3 & 50.6 \\
\hline AJ437618 & AEV-[NP:Ager:05] & Ageratum conyzoides & Nepal & 86.1 & 96.9 & 99.5 & 85.8 & 82.8 & 83.4 & 50.6 \\
\hline AM701770 & AEV-[PK:Fai:Bra:10] & Brassica rapa & Pakistan & 86.0 & 93.9 & 97.3 & 89.6 & 85.1 & 83.4 & 51.8 \\
\hline AF336806 & ChiLCV-[PK:Mul:Chi:07] & Capsicum spp. & Pakistan & 85.5 & 85.6 & 98.4 & 83.6 & 85.1 & 85.1 & 76.0 \\
\hline AJ875159 & ChiLCV-[Ba:Gaz:Tom:06] & S. lycopersicum & Bangladesh & 85.3 & 89.8 & 96.5 & 82.1 & 88.1 & 84.8 & 72.2 \\
\hline GU136803 & ChiLCV-[IN:Amr:Pap:09] & Carica papaya & India & 85.1 & 89.0 & 98.8 & 77.6 & 86.6 & 82.2 & 75.3 \\
\hline FN543099 & AEV-[IN:HP:Zin:09] & Zinnia elegance & India & 85.1 & 98.3 & 97.7 & 89.6 & 85.1 & 81.4 & 50.6 \\
\hline FJ177030 & JYMINV-[In:MP:Jat:08] & Jatropha gossypifolia & India & 85.0 & 92.4 & 94.9 & 65.7 & 55.2 & 80.6 & 59.8 \\
\hline DQ852623 & ToLCBaV-[In:Ker:Tom:05] & S. lycopersicum & India & 84.8 & 71.3 & 92.2 & 87.3 & 82.8 & 85.3 & 85.6 \\
\hline HM149260 & AEV-[In:UP:Pap:14] & Papaver somniferum & India & 84.7 & 95.7 & 95.2 & 88.7 & 86.6 & 80.6 & 50.6 \\
\hline FJ345402 & ChiLCV- [In:Pon:Ken:07] & Hibiscus cannabinus & India & 84.7 & 88.0 & 96.5 & 82.1 & 88.1 & 84.2 & 70.1 \\
\hline DQ673859 & ChiLCV-[In:Pun:Chi:07] & Capsicum spp. & India & 84.3 & 91.5 & 96.5 & 77.6 & 85.8 & 85.6 & 77.3 \\
\hline AF 165098 & ToLCBaV-[In:Ban:03] & Not available & India & 84.1 & 73.0 & 89.5 & 83.6 & 85.5 & 84.8 & 85.6 \\
\hline KF663698 & ToLCBaV-[In:Kar:Tom:13] & S. lycopersicum & India & 83.8 & 70.4 & 90.2 & 85.1 & 83.6 & 86.7 & 81.4 \\
\hline AF295401 & ToLCBaV-[In:Ban:Cot:05] & Gossypium spp. & India & 82.7 & 69.6 & 91.8 & 83.6 & 84.3 & 81.7 & 70.1 \\
\hline Z48182 & ToLCBaV-[In:05] & Not available & India & 82.3 & 70.4 & 90.2 & 85.8 & 83.6 & 81.9 & 72.2 \\
\hline
\end{tabular}

a Abbreviations: $\mathrm{AEV}=$ Ageratum enation virus, $\mathrm{TbCuSV}=$ Tobacco curly shoot virus, $\mathrm{ChiLCV}=$ Chili leaf curl virus, ToLCBaV = Tomato leaf curl Bangalore virus, ToLCKeV = Tomato leaf curl Kerala virus, and JYMINV = Jtropha yellow mosaic India virus.

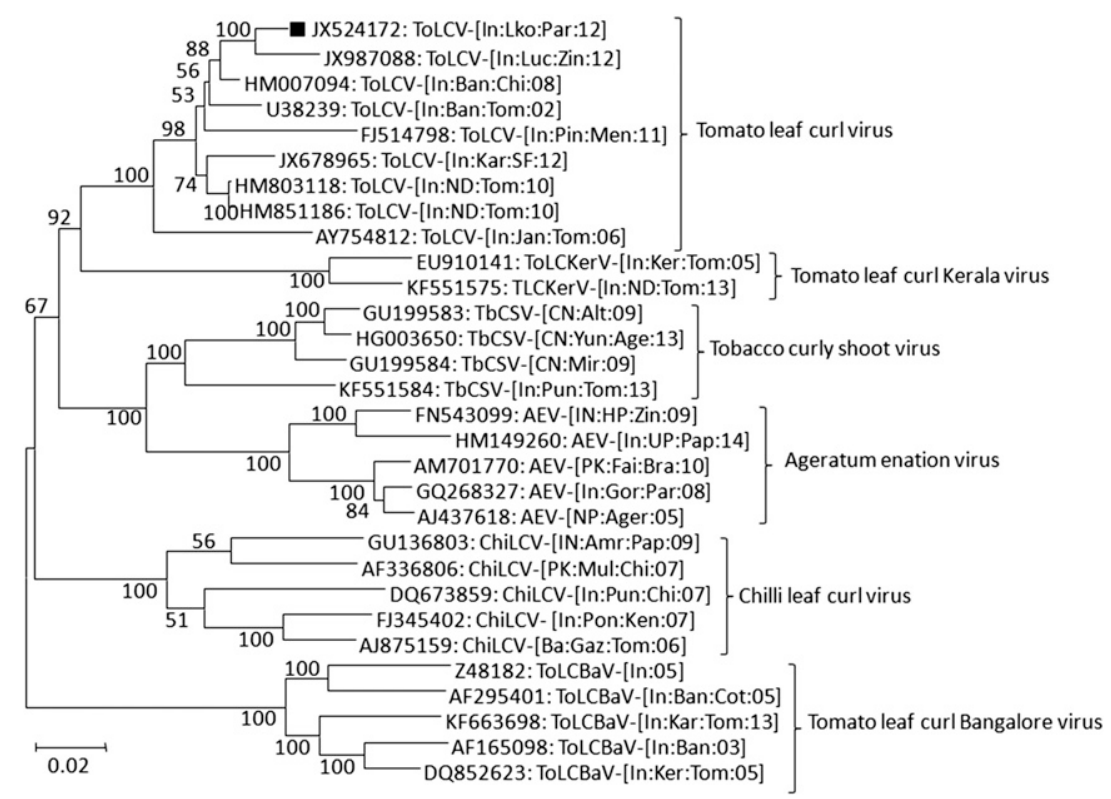

Fig. 2. Phylogenetic tree showing relationship of begomovirus isolate (JX524172) from Parthenium hysterophorus (indicated by $\mathbf{\square})$ with other begomoviruses. The tree was constructed using MEGA v6.1 tool and using the neighbor-joining method with 1,000 bootstrap replicates. 
ToLCV in P. hysterophorus. The approximately $1.4-\mathrm{kb} \alpha$-satellite and $\beta$-satellite components obtained from the SKR11 sample were sequenced and deposited in GenBank under accession numbers JX570736 (SKR11- $\alpha$-satellite) and JX987089 (SKR11- $\beta$-satellite).

The 1,389 nt of the SKR11- $\alpha$-satellite encodes for a replicationassociated protein (Rep) that is similar to the master Rep protein encoded by the genomic components (DNA-R) of nanoviruses (Zhang et al. 2012). It also has an A-rich region and a predicted hairpin structure. The nucleotide sequence analysis of the SKR11$\alpha$-satellite isolate showed 87.2 to $97.0 \%$ identity with isolates of AYVIA (JQ012793, AJ512948, and AJ512958) (Table 2). High amino acid sequence identities (94.0 to $98.7 \%$ ) were also observed for the
$\alpha$-Rep of SKR11- $\alpha$-satellite with those of AYVIA isolates (Table 2). The phylogenetic analysis also showed the closest relationships of SRKR11- $\alpha$-satellite with isolates of AYVIA (JQ012793, AJ512948, LK054802, and AJ512958) (Fig. 3). Owing to the high sequence identity and close relationships, the SKR11- $\alpha$-satellite was identified as AYVIA, for which the isolate descriptor AYVIA-[In:Lko:Par:12] is proposed.

Sequence analysis of the SKR11- $\beta$-satellite revealed 1,367 nt that encode for a conserved $\beta \mathrm{C} 1 \mathrm{ORF}$ in the complementary-sense orientation as well as the satellite conserved region and an A-rich region. The pairwise sequence identity of the complete SKR11- $\beta$-satellite sequence revealed 83.5 to $85 \%$ nucleotide identities with $\mathrm{PaLCuB}$

Table 2. Percent nucleotide sequence identity (Seq ID) and amino acid sequence identity of Ageratum yellow vein India $\alpha$-satellite (AYVIA)-[In:Lko:Par:12] (JX570736) and the encoded $\alpha$-replication-associated protein, respectively, with selected $\alpha$-satellite sequences from the databases

\begin{tabular}{|c|c|c|c|}
\hline \multirow[b]{2}{*}{ Accessions } & \multirow[b]{2}{*}{ Acronyms (isolate descriptors) } & \multicolumn{2}{|c|}{$\operatorname{Seq}(I D)(\%)^{\mathrm{a}}$} \\
\hline & & nt & $\overline{\mathbf{a a}}$ \\
\hline JQ012793 & Ageratum yellow vein India $\alpha$-satellite, AYVIA[In:Lko:Ama:13] & 97.0 & 98.7 \\
\hline AJ512948 & Ageratum yellow vein India $\alpha$-satellite, AYVIA-[PK:Age:04] & 95.1 & 97.8 \\
\hline AJ512958 & Ageratum yellow vein India $\alpha$-satellite, AYVIA-[In:Age:04] & 95.0 & 97.8 \\
\hline FN543100 & Ageratum yellow vein India $\alpha$-satellite, AYAIV-[In:HP:Zin:09] & 91.6 & 96.2 \\
\hline LK054802 & Ageratum yellow vein India $\alpha$-satellite, AYVIA-[In:HP:Mir:14] & 90.7 & 98.7 \\
\hline HE861941 & Ageratum yellow vein India $\alpha$-satellite, AYVIA-[In:HP:Gly:12] & 88.9 & 94.6 \\
\hline AJ512950 & Ageratum yellow vein India $\alpha$-satellite, AYVIA -[PK:Hib:04] & 88.4 & 94.3 \\
\hline AJ512951 & Ageratum yellow vein India $\alpha$-satellite, AYVIA-[PK:Age:04] & 87.9 & - \\
\hline AM930246 & Ageratum yellow vein India $\alpha$-satellite, AYVIA-[PK:Fai:Son:10] & 87.4 & 93.7 \\
\hline AM930244 & Ageratum yellow vein India $\alpha$-satellite, AYVIA-[PK:Fai:Son:10] & 87.2 & 94.0 \\
\hline AM930248 & Ageratum yellow vein India $\alpha$-satellite, AYVIA-[PK:Fai:Son:10] & 87.2 & 94.0 \\
\hline AJ579359 & Tomato yellow leaf curl Thailand $\alpha$-satellite, ToYLCuTA-[Th:Tom:03] & 83.1 & 89.5 \\
\hline AJ579356 & Tomato yellow leaf curl China $\alpha$-satellite, ToYLCuCNA-[Chi:Yun:Tom:03] & 82.6 & 91.4 \\
\hline AJ579347 & Tobacco curly shoot $\alpha$-satellite, TbCuSA-[CN:Yun:Tob:03] & 82.2 & 91.7 \\
\hline FN806782 & Sida yellow vein $\alpha$-satellite, SYVA-[CN:Yun:Sid:10] & 82.1 & 90.8 \\
\hline EU384636 & Gossypium darwinii symptomless $\alpha$-satellite, GDSA-[PK:Mul:Cot:09] & 81.3 & 88.6 \\
\hline FN658730 & Cotton leaf curl Burewala $\alpha$-satellite, CoLCuBA-[In:Raj:Cot:12] & 81.2 & 88.6 \\
\hline AM236765 & Malvastrum yellow mosaic $\alpha$-satellite, MYMA-[CN:Mal:08] & 82.1 & 91.1 \\
\hline AM050734 & Sida leaf curl $\alpha$-satellite, SLCuA-[CN:Hai:Sid:06] & 80.7 & 91.4 \\
\hline AJ238493 & Ageratum yellow vein $\alpha$-satellite, AYVA-[Sin:Age:99] & 80.1 & 89.8 \\
\hline EU384654 & Gossypium davidsonii symptomless $\alpha$-satellite, GDSA-[PK:Mul:Cot:09] & 67.2 & 57.6 \\
\hline FM164939 & Tomato leaf curl Pakistan $\alpha$-satellite, ToLCuPA-[PK:Fai:Eup:09] & 66.7 & 47.3 \\
\hline FJ218494 & Gossypium mustelinum symptomless $\alpha$-satellite, GMSA-[PK:Cot:12] & 66.4 & 56.8 \\
\hline AJ416153 & Ageratum yellow vein Singapore $\alpha$-satellite, AYVA-[Sin:Age:02] & 61.8 & 40.5 \\
\hline
\end{tabular}

a Abbreviations: $\mathrm{nt}=$ nucleotide, $\mathrm{aa}=$ amino acid, and $-=$ sequences were smaller; therefore, identity could not be obtained in the species demarcation tool.

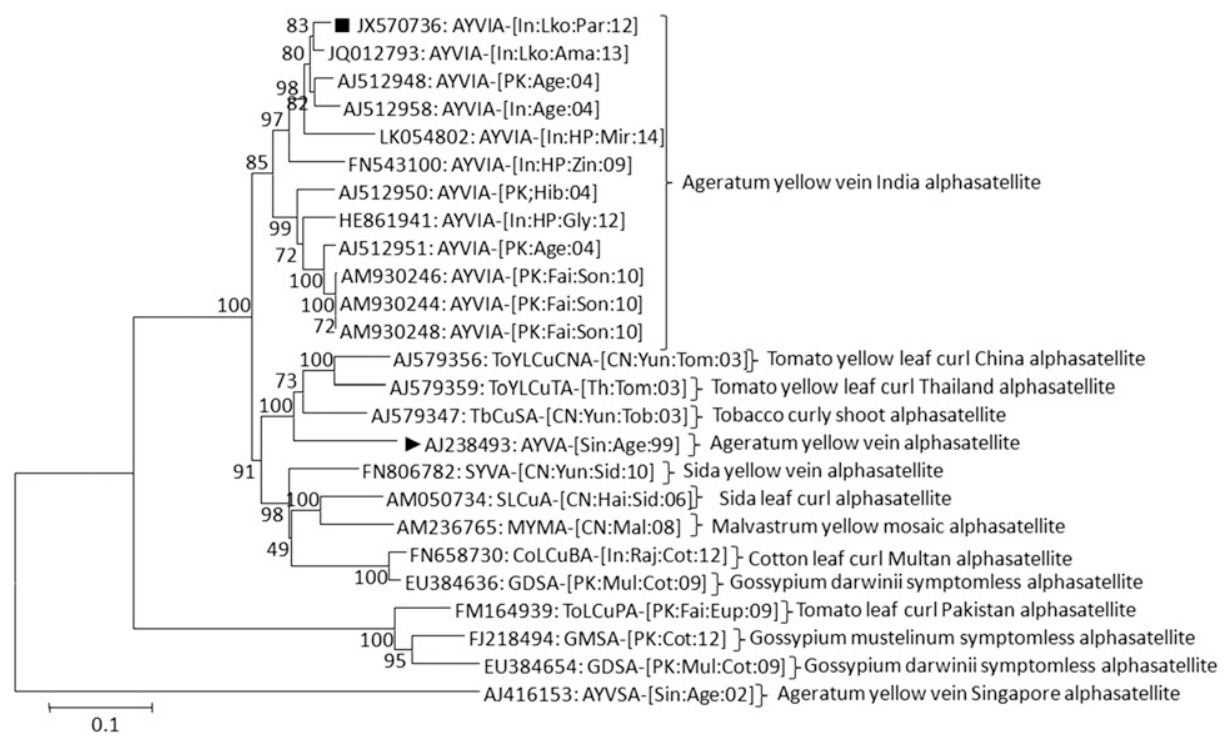

Fig. 3. Phylogenetic tree showing relationship of $\alpha$-satellite (JX570736) isolated from Parthenium hysterophorus (indicated by $\mathbf{~})$ with other $\alpha$-satellite sequences. The tree was constructed using MEGA v6.1 tool and using the neighbor-joining method with 1,000 bootstrap replicates. The Ageratum yellow vein $\alpha$-satellite (AYVA-[Sin:Age:99], AJ238493) reported from Singapore (shown by - ) is also considered for analysis. The tree is rooted on Ageratum yellow vein Singapore $\alpha$-satellite (AYVSA-[Sin:Age:02], AJ416153). 
sequences (AY438557, AY244706, AY230138, and DQ118862), and lower identities with other selected $\beta$-satellites (Table 3). The $\beta C 1$ ORF of the SKR11- $\beta$-satellite showed 97.5 to $100 \%$ amino acid sequence identity with corresponding ORF of $\mathrm{PaLCuB}$ isolates (Table 3). The phylogenetic analysis showed the close relationships of SKR11- $\beta$-satellite with isolates of $\mathrm{PaLCuB}$, and these isolates clustered together in a monophyletic group (Fig. 4). Because of the high sequence identity and close relationships with $\mathrm{PaLCuB}$, the SKR11- $\beta$-satellite was identified as isolate of $\mathrm{PaLCuB}$, for which isolate descriptor PaLCuB-[In:Lko:Par:12] is proposed.

Infectivity assays. The infectivity assay was conducted with agroinfectious clones of ToLCV-[In:Lko:Par:12], PaLCuB-[In:Lko:Par:

Table 3. Percent nucleotide sequence identity (Seq ID) and amino acid sequence identity of Papaya leaf curl $\beta$-satellite (PaLCuB)-[In:Lko:Par:12] (JX987089) and the encoded $\beta C 1$, respectively, with selected $\beta$-satellite sequences from the databases

\begin{tabular}{|c|c|c|c|}
\hline \multirow[b]{2}{*}{ Accessions } & \multirow[b]{2}{*}{ Acronyms (isolate descriptors) } & \multicolumn{2}{|c|}{ Seq ID $(\%)^{\mathbf{a}}$} \\
\hline & & nt & $\overline{\mathbf{a a}}$ \\
\hline DQ118862 & Papaya leaf curl $\beta$-satellite, PaLCuB-[IN:Chi:05] & 85.0 & 100.0 \\
\hline AY230138 & Papaya leaf curl virus $\beta$-satellite, PaLCuB-[IN:Jab:03] & 84.1 & 99.2 \\
\hline AY244706 & Papaya leaf curl virus $\beta$-satellite, PaLCuB-[IN:ND:03] & 83.3 & 98.3 \\
\hline AY438557 & Papaya leaf curl virus $\beta$-satellite, PaLCuB-[IN:Mb:05] & 83.5 & 97.5 \\
\hline AJ542490 & Tomato leaf curl $\beta$-satellite, ToLCB-[IN:ND:02] & 65.2 & 66.1 \\
\hline AY765255 & Tomato leaf curl $\beta$-satellite, ToLCB-[IN:Lud:04] & 64.8 & 65.0 \\
\hline AJ316036 & Tomato leaf curl $\beta$-satellite, ToLCuB-PK:RYK:97] & 64.3 & 65.3 \\
\hline AY728263 & Tomato leaf curl $\beta$-satellite, ToLCB-[IN:CP:04] & 65.6 & 63.6 \\
\hline AJ704610 & Tomato leaf curl China $\beta$-satellite, ToLCCNB-[CN:Gx16:02] & 60.9 & 46.6 \\
\hline AJ704609 & Tomato leaf curl China $\beta$-satellite, ToLCCNB-[CN:Gx 14:02] & 59.9 & 45.8 \\
\hline AJ704611 & Tomato leaf curl China $\beta$-satellite, ToLCCNB-[CN:Gx 17:02] & 60.8 & 46.6 \\
\hline AJ704612 & Tomato leaf curl China $\beta$-satellite, ToLCCNB-[CN:Gx 18:02] & 61.6 & 48.3 \\
\hline AJ704613 & Tomato leaf curl China $\beta$-satellite, ToLCCNB-[CN:Gx22:02] & 60.9 & 48.3 \\
\hline
\end{tabular}

a Abbreviations: aa $=$ amino acid and $\mathrm{nt}=$ nucleotide.

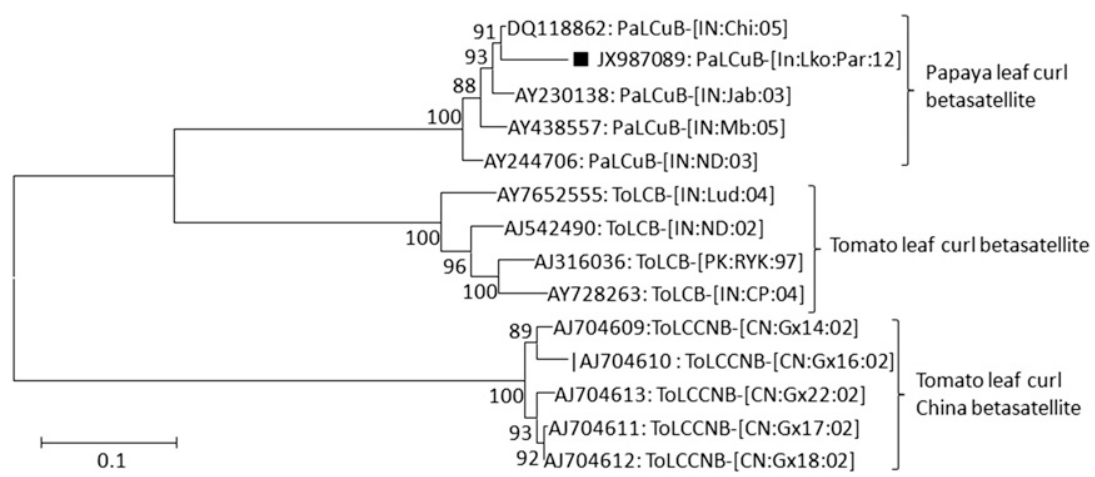

Fig. 4. Phylogenetic tree showing the relationship of the $\beta$-satellite isolated from Parthenium hysterophorus (JX987089, indicated by $\mathbf{~})$ with selected other $\beta$-satellites. The tree was constructed using MEGA v6.1 tool and using the neighbor-joining method with 1,000 bootstrap replicates.

Table 4. Infectivity assay using seedlings of Parthenium hysterophorus and Solanum lycopersicum and agroinfectious clones of Tomato leaf curl virus (ToLCV)[In:Lko:Par:12] (Par-A), Papaya leaf curl $\beta$-satellite (PaLCuB)-[In:Lko:Par:12] (Par- $\beta$ ), and Ageratum yellow vein India $\alpha$-satellite (AYVIA)-[In:Lko:Par:12] $(\operatorname{Par}-\alpha)$ DNA

\begin{tabular}{|c|c|c|c|c|c|c|c|}
\hline \multirow[b]{2}{*}{ Seedling, agroinfectious clones } & \multirow[b]{2}{*}{ Symptoms $^{b}$} & \multicolumn{3}{|c|}{ Symptomatic/inoculated plants } & \multicolumn{3}{|c|}{ Detection of ${ }^{a}$} \\
\hline & & Experiment 1 & Experiment 2 & Experiment 3 & ToLCV & PaLCuB & $\overline{\text { AYVIA }}$ \\
\hline \multicolumn{8}{|l|}{ P. hysterophorus } \\
\hline Par-A & Mild leaf curl & $9 / 10$ & $10 / 10$ & $9 / 10$ & $28 / 30$ & $0 / 30$ & $0 / 30$ \\
\hline Par-A+Par- $\beta$ & Severe leaf curl & $10 / 10$ & $9 / 10$ & $9 / 10$ & $28 / 30$ & $28 / 30$ & $0 / 30$ \\
\hline Par-A+Par- $\beta+$ Par $-\alpha$ & Severe leaf curl & $10 / 10$ & $10 / 10$ & $9 / 10$ & $29 / 30$ & $29 / 30$ & $29 / 30$ \\
\hline Par-A+Par- $\alpha$ & Mild leaf curl & $7 / 10$ & $8 / 10$ & $8 / 10$ & $23 / 30$ & $0 / 30$ & $23 / 30$ \\
\hline $\operatorname{Par}-\beta$ & No symptoms & $0 / 10$ & $0 / 10$ & $0 / 10$ & $0 / 30$ & $0 / 30$ & $0 / 30$ \\
\hline $\operatorname{Par}-\alpha$ & No symptoms & $0 / 10$ & $0 / 10$ & $0 / 10$ & $0 / 30$ & $0 / 30$ & $0 / 30$ \\
\hline \multicolumn{8}{|l|}{ S. lycopersicum } \\
\hline Par-A & Mild yellowing & $8 / 10$ & $9 / 10$ & $7 / 10$ & $24 / 30$ & $0 / 30$ & $0 / 30$ \\
\hline Par-A+Par- $\beta$ & Yellowing \& leaf curl & $9 / 10$ & $9 / 10$ & $10 / 10$ & $28 / 30$ & $28 / 30$ & $0 / 30$ \\
\hline Par-A+Par- $\beta+$ Par $-\alpha$ & Yellowing \& leaf curl & $10 / 10$ & $10 / 10$ & $9 / 10$ & $29 / 30$ & $29 / 30$ & $29 / 30$ \\
\hline Par-A+Par- $\alpha$ & Mild yellowing & $8 / 10$ & 910 & $8 / 10$ & $25 / 30$ & $0 / 30$ & $25 / 30$ \\
\hline $\operatorname{Par}-\beta$ & No symptoms & $0 / 10$ & $0 / 10$ & $0 / 10$ & $0 / 30$ & $0 / 30$ & $0 / 30$ \\
\hline $\operatorname{Par}-\alpha$ & No symptoms & $0 / 10$ & $0 / 10$ & $0 / 10$ & $0 / 30$ & $0 / 30$ & $0 / 30$ \\
\hline
\end{tabular}

${ }^{a}$ Fourth systemically infected leaf (from the top) was used for polymerase chain reaction (PCR) detection. Amplifications during PCR were obtained using degenerate primers of begomovirus, $\beta$-satellite, and $\alpha$-satellite DNA (detailed in Materials and Methods).

b Symptoms by 35 days postinoculation. 
12], and AYVIA-[In:Lko:Par:12] DNA. P. hysterophorus and S. lycopersicum plants agroinoculated with the Par-A+Par- $\beta+P a r-\alpha$ and ParA+Par- $\beta$ DNA developed prominent leaf curl and leaf curl accompanied with yellowing (only in tomato) symptoms, respectively, by 35 days postinoculation (dpi) (Table 4; Supplementary Fig. S1). The symptoms that developed in experimentally infected $P$. hysterophorus plants were indistinguishable from the symptoms observed in $P$. hysterophorus plants in the field. Plants inoculated with Par-A alone and in combination with Par- $\alpha$ (Par-A+Par- $\alpha$ ) developed mild symptoms, whereas no symptoms were observed when plants were inoculated either with Par- $\beta$ or Par- $\alpha$ alone, or mock inoculated (Table 4). This satisfies Koch's postulates for ToLCV with PaLCuB causing leaf curl disease of $P$. hysterophorus.

The presence or absence of ToLCV, AYVIA, and PaLCuB DNA in the leaves developing after inoculation of both $P$. hysterophorus and S. lycopersicum (agroinoculated plants) were assessed by PCR with the respective specific primers. The ToLCV DNA was detected in newly emerged leaves of plants agroinoculated with Par-A alone as well as in combinations with Par-A+Par- $\beta$ and Par-A+Par- $\alpha$. PaL$\mathrm{CuB}$ and AYVIA DNA were also detected in $P$. hysterophorus and $S$. lycopersicum plants, respectively, agroinoculated with Par-A+Par$\beta+$ Par- $\alpha$ (Table 4; Supplementary Fig. S2). These results indicated that ToLCV can replicate and move independently or in combinations with PaLCuB and AYVIA in inoculated plants. The mild symptoms in the plants inoculated with AYVIA together with ToLCV suggested that the $\alpha$-satellite is not required for symptom development in P. hysterophorus as well as in S. lycopersicum.

\section{Discussion}

The study presented here has, for the first time, shown infection of the weed $P$. hysterophorus with ToLCV, PaLCuB and AYVIA in India. Koch's postulates were satisfied by showing that agroinfiltration of the complex of ToLCV, PaLCuB, and AYVIA could induce leaf curl and stunting in P. hysterophorus (Table 4) which were indistinguishable from the symptoms seen in naturally infected plants in the field (Fig. 1). Moreover, severe leaf curl symptom in P. hysterophorus plants was observed when ToLCV together with $\mathrm{PaLCuB}$ was inoculated, whereas ToLCV alone or in combination with AYVIA induced only mild leaf curl. Our finding shows that the $\beta C 1$ protein of $\mathrm{PaLCuB}$ is a dominant symptom determinant. The $\beta C 1$ gene encoded by $\beta$-satellite has been well documented as a symptom modulator (Mansoor et al. 2003; Zhou 2013). The $\alpha$-satellites have no obvious contribution to symptoms induced by begomovirus- $\beta$-satellite disease complexes and appear to affect $\beta$-satellite replication but do not affect helper virus replication (Nawaz-ul-Rehman et al. 2010). Nawaz-ul-Rehman et al. (2010) observed that the $\alpha$-Rep proteins encoded by two nonpathogenic $\alpha$-satellites (Gossypium darwinii symptomless $\alpha$-satellite and Gossypium mustelinium symptomless $\alpha$-satellite) associated with Cotton leaf curl Multan virus can interact with Cotton leaf curl Rajasthan virus (CLCuRaV) Rep proteins and affect $\beta$-satellite replication but do not affect helper virus replication.

The infectivity of these agroinfectious-cloned DNA was also assessed in tomato (S. lycopersicum Pusa Ruby, the host from which ToLCV was first identified), where a complex of ToLCV, PaLCuB, and AYVIA induced severe leaf curl symptoms (Table 4). Agroinoculation of ToLCV alone in tomato induced mild yellowing only, whereas plants showed leaf curl when inoculated together with PaL$\mathrm{CuB}$, strengthening the observations that $\mathrm{PaLCuB}$ exacerbates the severity of ToLCV whereas AYVIA has no role in symptom modulation. The infections of ToLCV in tomato have been reported from India (Chakraborty et al. 2003; Chatchawankanphanich and Maxwell 2002; Chatchawankanphanich et al. 1993; Gaikwad et al. 2011; Kumar et al. 2012; Muniyappa et al. 2000; Shelat et al. 2014). A study carried out by Chatchawankanphanich and Maxwell (2002) suggested that particle bombardment of ToLCV-[In:Ban:Tom:02] alone in tomato ('Flora Dade', 'Hayslip', and 'Geneva 80') may induce leaf curl and yellowing symptoms, though it takes a longer time (45 dpi) to develop such symptoms. In our case, only mild yellowing was observed in Pusa Ruby tomato plants inoculated with ToLCV-[In:Lko:Par:12] alone; however, symptoms developed within 35 dpi and remained mild throughout the plant's life. The variation in symptoms may be due to differences in tomato cultivar, as was observed in case of okra varieties by Venkataravanappa et al. (2013), as well as sequence diversity of both ToLCV isolates, because ToLCV[In:Ban:Tom:02] (Chatchawankanphanich and Maxwell 2002) shares 96.3\% nucleotide identity with our ToLCV isolate. In addition to the report of ToLCV infection in tomato, association of ToLCV sunflower leaf curl disease in India (Vanitha et al. 2013) and with different $\beta$-satellites (cotton leaf curl Multan $\beta$-satellite) causing leaf deformity and stunting in mentha (Borah et al. 2010) is reported. Moreover, unpublished reports on the occurrence of $\mathrm{PaLCuB}$ associated with Papaya leaf curl virus in Delhi (AY244706), Mungbean yellow mosaic India virus in Gujarat (DQ118862), and ToLCV in Jabalpur (AY230138) and Andhra Pradesh (AY438557) in India are available in the GenBank database. However, occurrence of the complex of ToLCV, PaLCuB, and AYVIA which is being reported here is not known.

Weeds have been reported to be hosts of crop-infecting begomoviruses, which can lead to increased virus incidence and losses in agricultural crops grown (Bedford et al. 1998; Kashina et al. 2003; Tavares et al. 2012; Barreto et al. 2013). Here, using the infectious clones of ToLCV[In:Lko:Par:12] and PaLCuB-[In:Lko:Par:12], we also established that this complex induces severe leaf curl symptoms in tomato, and it is possible that $P$. hysterophorus acts as a reservoir for ToLCV in tomato. Therefore, $P$. hysterophorus infected with ToLCV could lead to increased virus incidence and losses in adjacent tomato fields. The removal of this weed may be recommended to reduce inoculum pressure.

\section{Acknowledgments}

We thank the director of the CSIR-National Botanical Research Institute, Lucknow, India for facilities and the Department of Science and Technology, Government of India for a fellowship to S. Kumar. Plant Microbe and Soil Interactions project (BSC 0117), funded by CSIR, New Delhi, partially support this study.

\section{Literature Cited}

Akhtar, N., Satyam, A., Anand, V., Verma, K. K., Khatri, R., and Sharma, A. 2010. Dysregulation of $\mathrm{T}_{\mathrm{H}}$ type cytokines in the patients of Parthenium induced contact dermatitis. Clin. Chim. Acta 411:2024-2028.

Barreto, S. S., Hallwass, M., Aquino, O. M., and Inoue-Nagata, A. K. 2013. A study of weeds as potential inoculum sources for a tomato-infecting begomovirus in central Brazil. Phytopathology 103:436-444.

Bedford, I. D., Kelly, A., Banks, G. K., Briddon, R. W., Cenis, J. L., and Markham, P. G. 1998. Solanum nigrum: An indigenous weed reservoir for a tomato yellow leaf curl geminivirus in southern Spain. Eur. J. Plant Pathol. 104:221-222.

Borah, B. K., Cheema, X., Gill, C. K., and Dasgupta, I. 2010. A geminivirussatellite complex is associated with leaf deformity of mentha (mint) plants in Punjab. Indian J. Virol. 21:103-109.

Briddon, R. W., Brown, J. K., Moriones, E., Stanley, J., Zerbini, M., Zhou, X., and Fauquet, C. M. 2008. Recommendations for the classification and nomenclature of the DNA- $\beta$ satellites of begomoviruses. Arch. Virol. 153:763-781.

Briddon, R. W., Bull, S. E., Amin, I., Idris, A. M., Mansoor, S., Bedford, I. D., Dhawan, P., Rishi, N., Siwatch, S. S., Abdel-Salam, A. M., Brown, J. K., Zafar, Y., and Markham, P. G. 2003. Diversity of DNA- $\beta$, a satellite molecule associated with some monopartite begomoviruses. Virology 312:106-121.

Briddon, R. W., Bull, S. E., Amin, I., Mansoor, S., Bedford, I. D., Rishi, N., Siwatch, S. S., Zafar, Y., Abdel-Salam, A. M., and Markham, P. G. 2004 Diversity of DNA 1: A satellite-like molecule associated with monopartite begomovirus-DNA- $\beta$ complexes. Virology 324:462-474.

Briddon, R. W., Mansoor, S., Bedford, I. D., Pinner, M. S., and Markham, P. G. 2000. Clones of cotton leaf curl geminivirus induce symptoms atypical of cotton leaf curl disease. Virus Genes 20:19-26.

Brown, J. K., Murilo-Zerbini, F., Navas-Castillo, J., Moriones, E., RamosSobrinho, R., Silva, J. C. F., Fiallo-Olivé, E., Briddon, R. W., HernándezZepeda, C., Idris, A., Malathi, V. G., Martin, D. P., Rivera-Bustamante, R., Ueda, S., and Varsani, A. 2015. Revision of Begomovirus taxonomy based on pairwise sequence comparisons. Arch. Virol. 160:1593-1619.

Bull, S. E., Briddon, R. W., and Markham, P. G. 2003. Universal primers for the PCR-mediated amplification of DNA 1: A satellite-like molecule associated with begomovirus-DNA $\beta$ complexes. Mol. Biotechnol. 23:83-86.

Chakraborty, S., Pandey, P. K., Banerjee, M. K., and Kalloo, G. 2003. A new begomovirus species causing tomato leaf curl disease in Varanasi India. Plant Dis. 93:1485-1495.

Chatchawankanphanich, O., Chiang, B.-T., Green, S. K., Singh, S. J., and Maxwell, D. P. 1993. Nucleotide sequence of a geminivirus associated with tomato leaf curl from India. Plant Dis. 77:1168.

Chatchawankanphanich, O., and Maxwell, D. P. 2002. Tomato leaf curl Karnataka virus from Bangalore, India appears to be a recombinant Begomovirus. Phytopathology 92:637-645. 
Fauquet, C. M., Bisaro, D. M., Briddon, R. W., Brown, J. K., Harrison, B. D., Rybicki, E. P., Stenger, D. C., and Stanley, J. 2003. Revision of taxonomic criteria for species demarcation in the family Geminiviridae, and an updated list of begomovirus species. Arch. Virol. 148:405-421.

Gaikwad, K. A., Sharma, A., and Cheema, D. S. 2011. Molecular detection and characterization of leaf curl virus infecting tomato in Punjab, India. Acta Hortic. 914:153-156.

Gnanavel, I. 2013. Parthenium hysterophorus L.: A major threat to natural and agro eco-systems in India. Sci. Int. 1:124-131.

Huang, C., Xie, Y., Zhao, L., Ren, H., and Li, Z. 2013. A naturally occurring defective DNA satellite associated with a monopartite begomovirus: Evidence for recombination between alphasatellite and betasatellite. Viruses 5: 2116-2128.

Kashina, B. D., Mabagala, R. B., and Mpunami, A. A. 2003. First report of Ageratum conyzoides L. and Sida acuta Burm F. as new weed hosts of Tomato yellow leaf curl Tanzania virus. Plant Prot. Sci. 39:18-22.

Kumar, S. P., Patel, S. K., Kapopara, R. G., Jasrai, Y. T., and Pandya, H. A. 2012. Evolutionary and molecular aspects of Indian Tomato leaf curl virus coat protein. Int. J. Plant Genomics 2012:Article 417935. doi:10.1155/2012/417935

Lapidot, M., Legg, J. P., Wintermantel, W. M., and Polston, J. E. 2014. Management of whitefly-transmitted viruses in open-field production systems. Adv. Virus Res. 90:147-206.

Mansoor, S., Briddon, R. W., Zafar, Y., and Stanley, J. 2003. Geminivirus disease complexes: An emerging threat. Trends Plant Sci. 8:128-134.

Moffat, A. S. 1999. Geminiviruses emerge as serious crop threat. Science 286: 1835.

Morin, L., Reid, A. M., Sims-Chilton, N. M., Buckley, Y. M., Dhileepan, K., Hastwell, G. T., Nordblom, T. L., and Raghu, S. 2009. Review of approaches to evaluate the effectiveness of weed biological control agents. Biol. Control 51:1-15.

Muhire, B. M., Varsani, A., and Martin, D. P. 2014. SDT: A virus classification tool based on pairwise sequence alignment and identity calculation. PLoS One 9:e108277.

Muniyappa, V., Venkatesh, H. M., Ramappa, H. K., Kulkarni, R. S., Zeidan, M., Tarba, C.-Y., Ghanim, M., and Czosnek, H. 2000. Tomato leaf curl virus from Bangalore (ToLCV-Ban4): Sequence comparison with Indian ToLCV isolates, detection in plants and insects, and vector relationships. Arch. Virol. 145: 1583-1598.

Nawaz-ul-Rehman, M. S., Briddon, R. W., and Fauquet, C. M. 2012. A melting pot of Old World begomoviruses and their satellites infecting a collection of Gossypium species in Pakistan. PLoS One 7:e40050.

Nawaz-ul-Rehman, M. S., Nahid, N., Mansoor, S., Briddon, R. W., and Fauquet, C. M. 2010. Post-transcriptional gene silencing suppressor activity of two non-pathogenic alphasatellites associated with a begomovirus. Virology 405: 300-308.
Padidam, M., Beachy, R. N., and Fauquet, C. M. 1995. Tomato leaf cur geminivirus from India has a bipartite genome and coat protein is not essential for infectivity. J. Gen. Virol. 76:25-35.

Paprotka, T., Metzler, V., and Jeske, H. 2010. The first DNA 1-like a satellites in association with New World begomoviruses in natural infections. Virology 404:148-157.

Prasada-Rao, R. D. J. V., Reddy, D. V. R., Nigam, S. N., Reddy, A. S., Waliyar, F., Reddy, T. Y., Subramanyam, K., Sudheer, N. J., Naik, K. S. S., Byopadhyay, A., Desai, S., Ghewe, M. P., Basu, M. S., and Somasekhar. 2003. Peanut Stem Necrosis: A New Disease of Groundnut in India. Inf. Bull. No. 67. International Crop Research Institute for the Semi-Arid Tropics, Patancheru, India.

Rojas, M. R., Gilbertson, R. L., Russell, D. R., and Maxwell, D. P. 1993. Use of degenerate primes in the polymerase chain reaction to detect whiteflytransmitted geminiviruses. Plant Dis. 77:340-347.

Sharma, V. K., Sethuraman, G., and Bhat, R. 2005. Evolution of clinical pattern of Parthenium dermatitis: A study of 74 cases. Contact Dermat. 53:84-88.

Sharman, M., Persley, D. M., and Thomas, J. E. 2009. Distribution in Australia and seed transmission of tobacco streak virus in Parthenium hysterophorus. Plant Dis. 93:708-712.

Shelat, M., Murari, S., Sharma, M. C., Subramanian, R. B., Jummanah, J., and Jarullah, B. 2014. Prevalence and distribution of Tomato leaf curl virus in major agroclimatic zones of Gujarat. Adv. Biosci. Biotechnol. 5:1-3.

Singh, H. P., Batish, D. R., Pandher, J. K., and Kohli, R. K. 2003. Assessment of allelopathic properties of Parthenium hysterophorus residues. Agric. Ecosyst. Environ. 95:537-541.

Tamura, K., Stecher, G., Peterson, D., Filipski, A., and Kumar, S. 2013. MEGA6: Molecular Evolutionary Genetics Analysis version 6.0. Mol. Biol. Evol. 30: 2725-2729.

Tavares, S. S., Ramos-Sobrinho, R., González-Aguilera, J., Lima, G. S. A. Assunção, I. P., and Zerbini, F. M. 2012. Further molecular characterization of weed-associated begomoviruses in Brazil with an emphasis on Sida spp. Planta Daninha 30:305-315.

Vanitha, L. S., Shankarappa, K. S., Rangaswamy, K. T., Wickramaarachchi, W. A. R. T., and Govindappa, M. R. 2013. Complete nucleotide sequence of tomato leaf curl Karnataka virus and $\beta$ satellite molecule associated with leaf curl disease on sunflower in India. Plant Pathol. J. 12:19-25.

Venkataravanappa, V., Reddy, C. N. L., and Reddy, M. K. 2013. Begomovirus characterization, and development of phenotypic and DNA-based diagnostics for screening of okra genotype resistance against Bhendi yellow vein mosaic virus. 3 Biotech 3:461-470.

Zhang, J., Wang, Y.-Q., Hou, H.-W., and Qian, Y.-J. 2012. Characterization of the replication-associated protein (Rep) promoter of an alpha-satellite associated with Tobacco curly shoot virus. Afr. J. Biotechnol. 11:3522-3530.

Zhou, X. 2013. Advances in understanding begomovirus satellites. Annu. Rev. Phytopathol. 51:357-381. 